\title{
Effect of Salicylic Acid Pretreatment on Yield, Its Components and Remobilization of Stored Material of Wheat under Drought Stress
}

\author{
Mehran Sharafizad ${ }^{1}$, Ahmad Naderi $^{2}$, Seyed Ata Siadat ${ }^{3}$, Tayeb Sakinejad ${ }^{4} \&$ Shahram Lak $^{5}$ \\ ${ }^{1} \mathrm{PhD}$. Student Department of Agronomy, Science and Research Branch, Islamic Azad University, Khouzestan, \\ Iran \\ ${ }^{2}$ Academic staff of Khuzestan research center, Iran \\ ${ }^{3}$ Professor of Department of Agronomy and Plant Breeding, Dezful Branch, Islamic Azad University khouzestan, \\ Iran \\ ${ }^{4}$ Department of Agronomy and Plant Breeding, Ahwaz Branch, Islamic Azad University, Ahwaz, Iran \\ ${ }^{5}$ Associated professor of Department of Agronomy and Plant Breeding, Science and Research Branch, Islamic \\ Azad University, khouzestan, Iran \\ Correspondence: Mehran Sharafizade, Department of Agronomy, Science and Research Branch, Islamic Azad \\ University, Khouzestan, Iran. Tel: 98-916-342-0052. E-mail: msharafizade@yahoo.com
}

Received: June 6, 2012 Accepted: July 3, 2012 Online Published: August 24, 2012

doi:10.5539/jas.v4n10p115 URL: http://dx.doi.org/10.5539/jas.v4n10p115

\begin{abstract}
Due to higher needs of food in growing populations leads to accelerate the efforts of food production now days. Yield which is obtained from cereal farm is not at the amount of what we expected from their genetic potential. So it is possible to use different agro-techniques to increase total yield and help the crops to reach their genetic potential. In order to investigate the effect of salicylic acid on total yield and yield component of wheat under stress condition an experiment was conducted base on split factorial design with three replications. Treatments were drought stress at three levels (control, drought stress in mid florescence and drought stress in grain filling stage). Second treatment was application of salicylic acid as a priming agent, foliar application at beginning of tillering and foliar application of salicylic acid at beginning of flowering, and the third treatment was different dosage of salicylic acid (0, 0.7, 1.2 and $2.7 \mathrm{mmol})$. Results of experiment showed that drought stress significantly decreased grain yield, efficiency of material distribution while the highest grain yield was obtained at non-stressed condition with application of $0.7 \mathrm{mmol}$ Salicylic acid. The highest redistribution of stored material, redistribution efficiency and partitioning was at time of salicylic application in vegetative stage, whereas the highest proportion of the metabolism in the grain yield observed in control condition (without stress). Grain yield exhibited high and positive correlation with number of spikes in $\mathrm{m}^{2}$, number of grain in spike, biological yield and harvest index.
\end{abstract}

Keywords: salicylic acid, yield, reverse mobilization, redistribution efficiency, partitioning

\section{Introduction}

\subsection{Effect of Abiotic Stresses on Plants}

Plants that are under stress before pollination usually due to lower photosynthetic activities store less products in their roots but even this situation reverse mobilization in stress conditions may higher compare to normal conditions. Performance and capacity of plant for transporting photo assimilates from main and sub-ordinary sources meaning active photosynthesis and reverse mobilization affects harvest index and grain yield. Effect of moisture stress on wheat depends on different developmental stage and it could significantly affect yield and other physiological traits (Euarrje \& Jones, 1979). Drought stress could induce florescence and maturation of Wheat crop (Oost Erhuis \& Cortwight, 1983). Mean percentage of reverse mobilization under drought was $(46.6 \%)$ is higher than normal condition (29.5). So it is concluded that reverse translocation under drought stress is more favorable than normal condition (Eberhand Doubrava, 1989). Drought stress in often happen after pollination in the arid environment and due to severe decrease in photosynthesis rate and amount of dry matter in grain will decrease and so other pathways are needed to provide losses for example translocation and reverse mobilization from vegetative organ to grain and as result loss in grain weight is recover (Gent, 1994). Water 
stress near florescence, significantly interfere grain formation and fertilization and resulted in lower number of grain with higher grain weight in spike. The reason of this phenomenon is decrease in competition for obtaining photosynthetic products while stress at grain filling, significantly lower translocation of photosynthetic products and resulted in wrinkle of grains and 1000 seed weight (Machado et al., 1993).

\subsection{Importance of Wheat Production}

Wheat is a cereal crop which is planted in nearly $17 \%$ of arable land all around the world. This crop is main source of food for more than $35 \%$ of world population due to its high energy. Using plant growth regulators like cycocel and Salicylic acid is a good strategy to waves some sue effects of drought stress. Salicylic acid plays a respiratory role in plants which are under environmental stress. Plant growth regulators controls physiological and biochemical responses of plants and modify plant's internal components and perform important changes that ultimately lead to changes in nutritional and environmental impacts associated with growth and are development (Chen et al., 1997). In addition regulatory roles of these compounds in root growth and development, yield and yield component is well understood (Khodary, S. E. A., 2004). There are some reports that Salicylic acid could increase salt tolerance in wheat seedling (Kang et al., 2002) and drought stress (Janda, 1999). Different biochemical and physiological responses of plants to salicylic acid were reported (Yusuf, 2008). These effects are ion absorption, membrane permeability and mitochondrial respiration (Glass, 1974). Treated wheat cultivars with salicylic acid (SA) exhibited higher final yield under different levels of drought stress. Wheat seed priming with $0.5 \mathrm{mmol}$ SA resulted high germination percentage comparing to control (Janda, 1999). Attention to high rate of redistribution of photosynthetic products in stress conditions, storage of enough non-structural carbohydrates in stem and other vegetative plant organs are necessary for supporting grain materials. This is especially important in severe stress conditions and at such conditions photosynthesis and correlated grin weight will decrease drastically

\subsection{Hypotheses and Aim of This Study}

Notably amount of grain weight in filling period is coming from active photosynthesis (Emam et al., 1996). And moisture reduction is grain filling is responsible for decrease in photosynthesis and lower grain weight. This is the latest member of yield determination and is the only part of total yield which is related to environment after florescence (Envns et al., 1993). Salicylic acid increased activity of antioxidant enzymes such as catalase, peroxidase and superoxide dismutase when it was sprayed on the wheat crop (Yusuf et al., 2008). Application of salicylic acid on wheat seedling resulted in big seed size, higher seed weight and total yield (Sakhabutdinova et al., 2003). This study was conducted with the aim of investigation salicylic acid effect on yield, yield component and reverse translocation in storage materials of wheat under drought conditions.

\section{Method}

\subsection{Location and Experimental Design}

This experiment was conducted in order to investigate the effect of salicylic acid on wheat growth and final yield under drought stress. Wheat genotype was Chamran, which is the most planted cultivar in Khuzestan providence of Iran. Design of experiment was split factorial with three replications. Main plot treatments were drought stress at three levels (control, drought stress in mid florescence and drought stress in grain filling stage). Second treatment was application of salicylic acid as a priming agent, foliar application at beginning of tillering and foliar application of salicylic acid at beginning of flowering, and the third treatment was different dosage of salicylic acid $(0,0.7,1.2$ and $2.7 \mathrm{mmol}) .100 \mathrm{~kg}$ ammonium super phosphate, $100 \mathrm{~kg}$ urea and $100 \mathrm{~kg}$ potassium sulphate were added to the farm before planting seeds and $100 \mathrm{~kg}$ urea was added to the field at tillering stage.

\subsection{Treatment Preparation and Formulae}

For priming treatment seeds were soaked in Salicylic acid concentration for 24 hour at different concentrations. In order to increase absorption area, seeds were inoculated by surfactant, toein $20 \%$ (Merck, Co.). To reduce any rainfall effects on drought stress treatment, each plot was covered by shelter protector. Investigated traits were number of spikes $\left(\mathrm{m}^{2}\right)$, Number of seed in spike, number of spike $\left(\mathrm{m}^{2}\right), 1000$ seed weight, final yield, biological yield and measurement of reverse mobilization was done base on Papakusta and Gagians, 1991) using following formula:

$$
\mathrm{A}=\mathrm{B}-\mathrm{C}
$$

A: Dry matter translocation in reverse mobilization $(\mathrm{gr} / \mathrm{m} 2)$

$$
\mathrm{D}=(\mathrm{A} / \mathrm{B}) \times 100
$$

D: Efficiency of reverse mobilization (\%) and B: the highest amount of vegetative dry matter except grain in 
pollination phase $(\mathrm{gr} / \mathrm{m} 2)$

$$
\mathrm{E}=(\mathrm{A} \times \mathrm{F}) \times 100
$$

$\mathrm{C}$ : dry matter of vegetative parts except grain in physiological maturation $\left(\mathrm{gr} / \mathrm{m}^{2}\right)$

$$
\mathrm{G}=100-\mathrm{E}
$$

$\mathrm{G}=$ proportion of reverse mobilization in grain yield (\%) and

$$
\mathrm{F}=\text { Grain yield in } \mathrm{m}^{2}
$$

Data analysis was performed using Mstat-C, Spss and Excel software.

\section{Results and Discussion}

\subsection{Statistics and Data Analysis}

Analysis of variance and mean comparison of this experiment shows that using salicylic acid could increase plant tolerance to environmental stress but it is significantly related to the time of application of salicylic acid.

\subsubsection{Number of Spikes in $\mathrm{m}^{2}$}

There was no significant effect on number of spike in m-2. Results showed that Seed priming with SA could increase number of spikes and stress at florescence exhibited the lowest number of spikes but effects were not statistically significant for this trait. There are some reports that moisture stress before pollination could decrease number of spikes in unit of area (Chodsi \& Roberts, 2005; Sonudgunta \& Fisher, 1979).

\subsubsection{Number of Grain in Spikes}

In the recent years higher grain yield is mostly due $t$ increase in the number of grain in the spike or in planted area and increase in grain weight had a less proportion in yield increase (Clderin et al., 1999). Results of experiment showed that number of grain in spike is influenced by stress, different dosage of SA and interaction of time of SA application and effects of stress was not significant. No stress condition exhibited the heights (36.5) and stress in mid florescence exhibited the lowest (17.88) number of grain in spike. Also number of grain at stress condition in grain filling was (29.44) (Figure 1, 2,3). Singh et al 1996 reported that plants have especial suitability to drought stress and stress at this time could have considerable decrease in number of grain in spikes (Saini \& Aspinall, 1981).

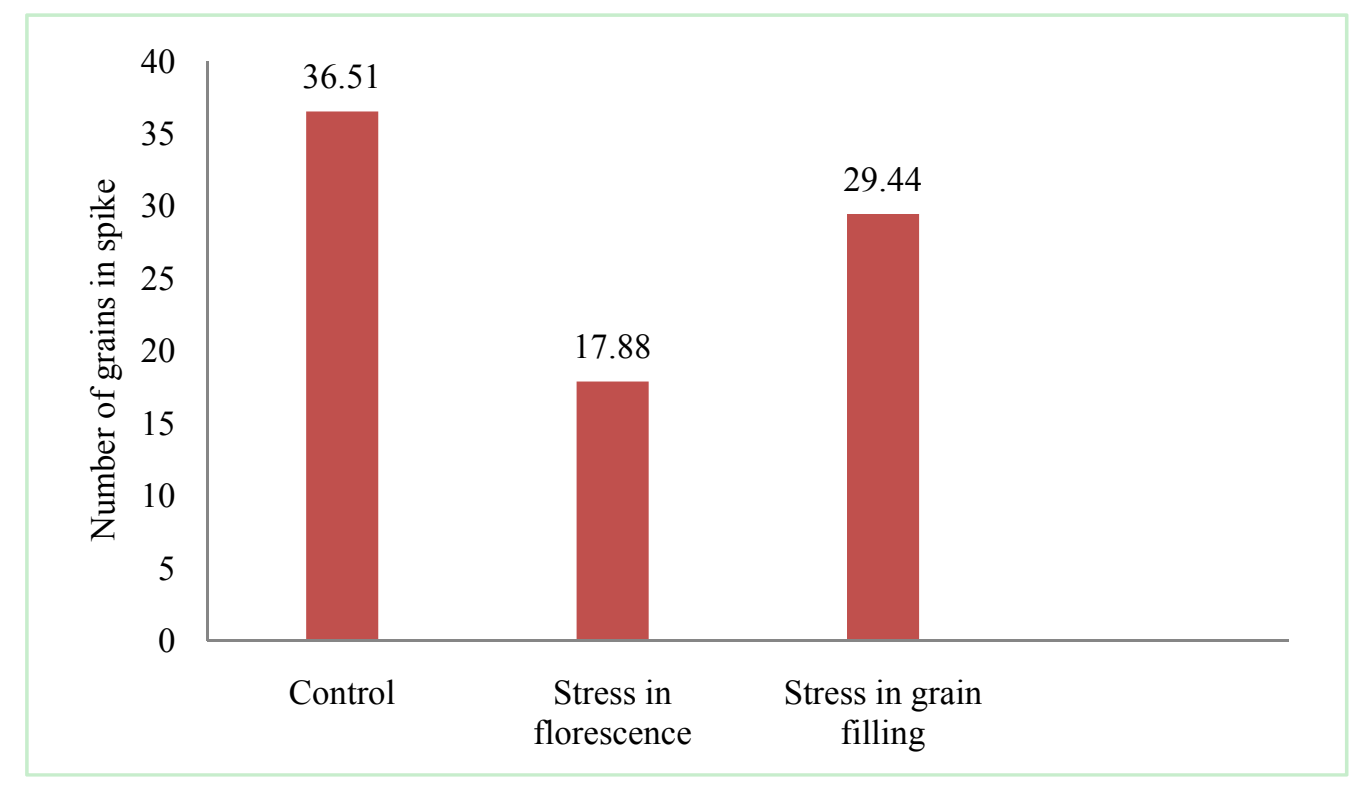

Figure 1. Effect of drought stress on number of grain in each spike at different developmental stages 


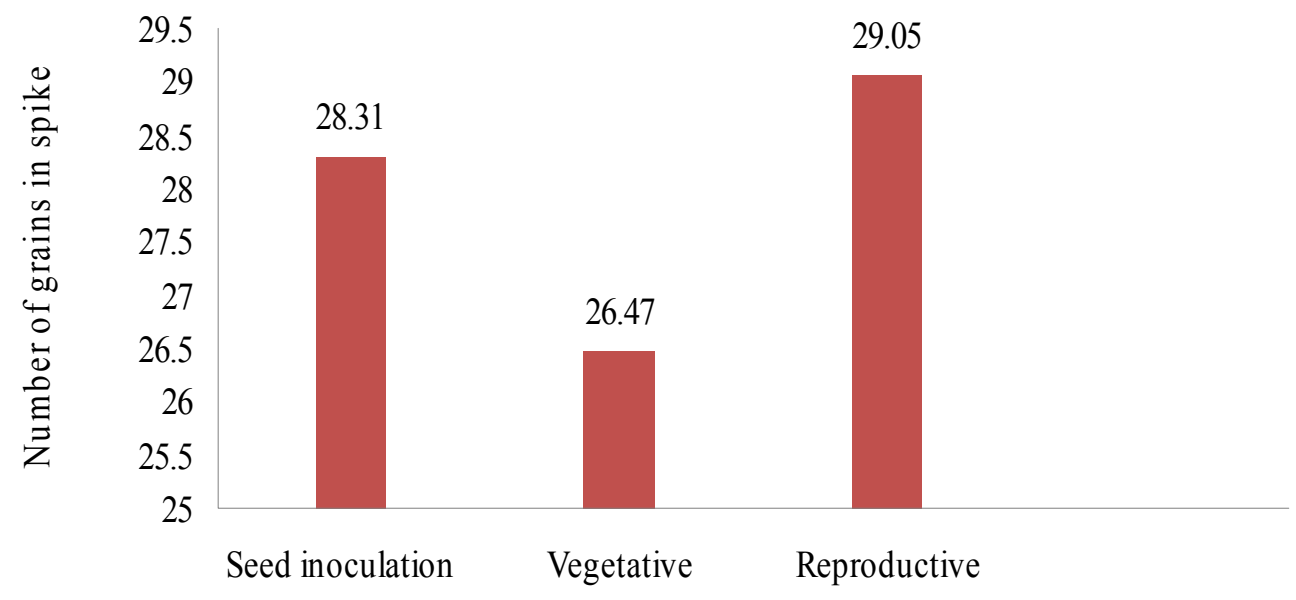

Figure 2. Effect of time of SA application on number of grain in each spike

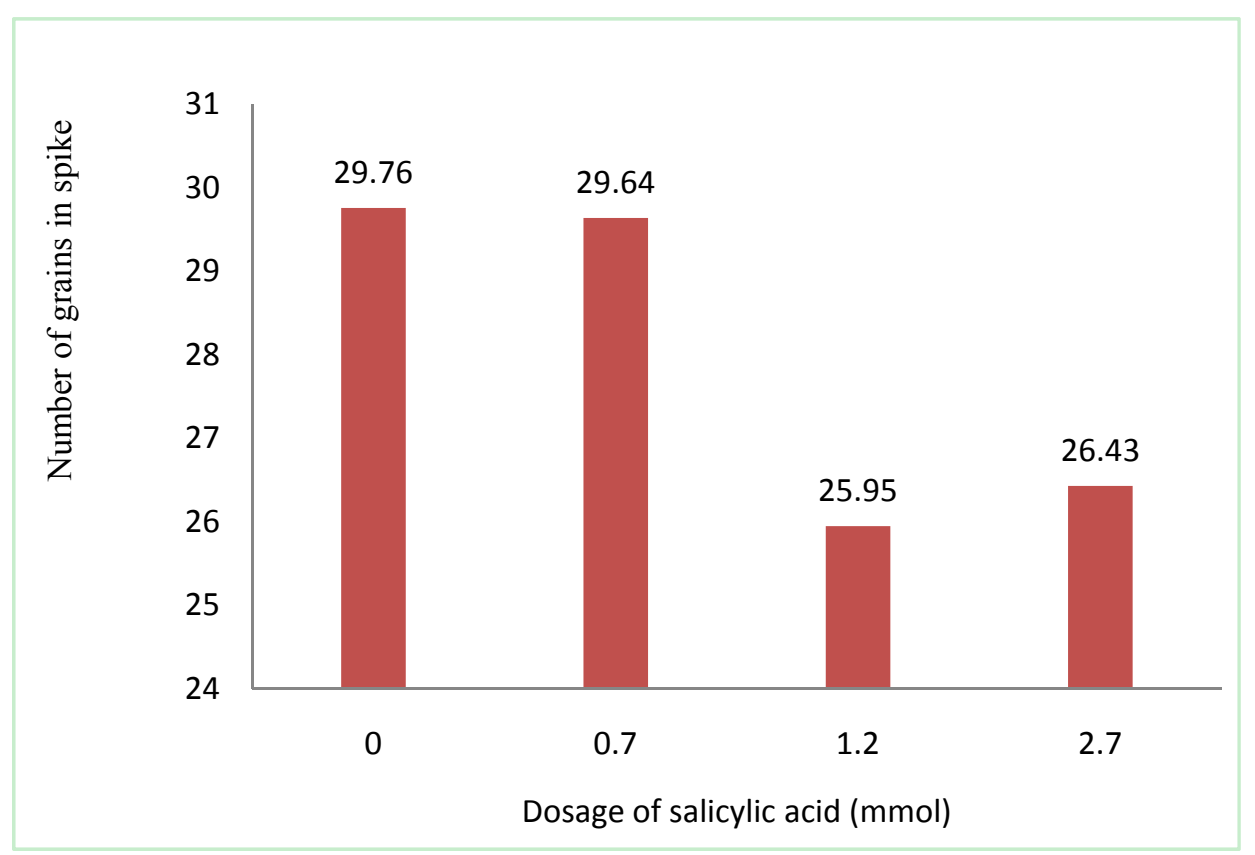

Figure 3. Effect of time of SA dosage on number of grain in each spike

\subsubsection{Seed Weight}

1000 seed weight is one of the most important parts of final wheat yield and it is determined by rate and duration of grain filling. Rate of grain filling is highly depends on genotype but duration of grain filing in depends on environment (Quarrie \& Jones, 1979). Results of this experiment showed that two way interaction of drought stress, time of SA application. As it shown in (Figure 4) the highest 1000 seed weight was achieved in stress in florescence (48 gr) while the lowest 1000 seed weight was achieved in grain filling (43.92 gr). Results showed that drought stress at stage of grain filling could significantly decrease 1000 seed weight. Drought stress in florescent or seed formation stages could significantly decrease fertility and might lead to lower number of seeds, this might due to the decreases in photosynthesis process (Machado et al., 1993). 


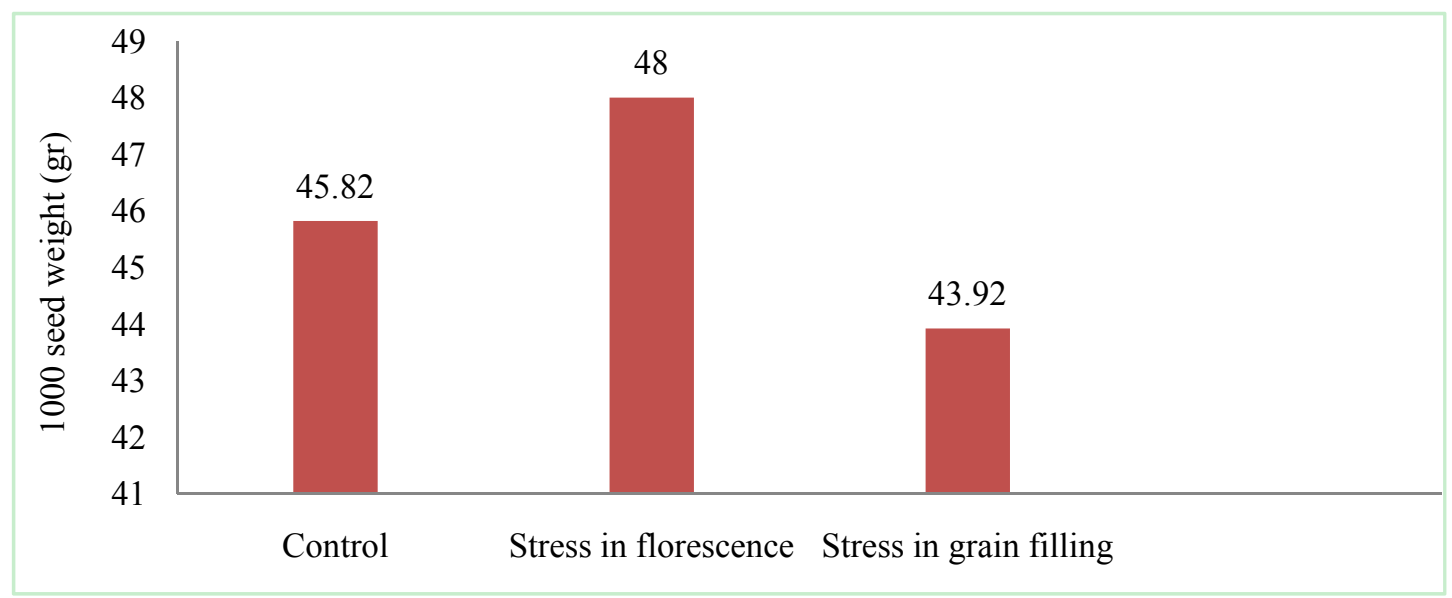

Figure 4. Effect of drought stress on 1000 seed weight at different developmental stages

\subsubsection{Total Grain Yield}

Main effects of drought stress and Dosage of SA significantly affected total grain yield. No stress treatment exhibited the highest yield and the lowest yield was exhibited in drought stress at florescence time of wheat (Figure 5). Sinand et al, 2003 reported that grain yield and duration of grain filling I influenced by drought and when the numbers of grains were constant in pollination stage weight is most important factor in wheat total yield. The highest yield was achieved by application of 0.7 (mmol) SA at vegetative stages of wheat (Figure 6).

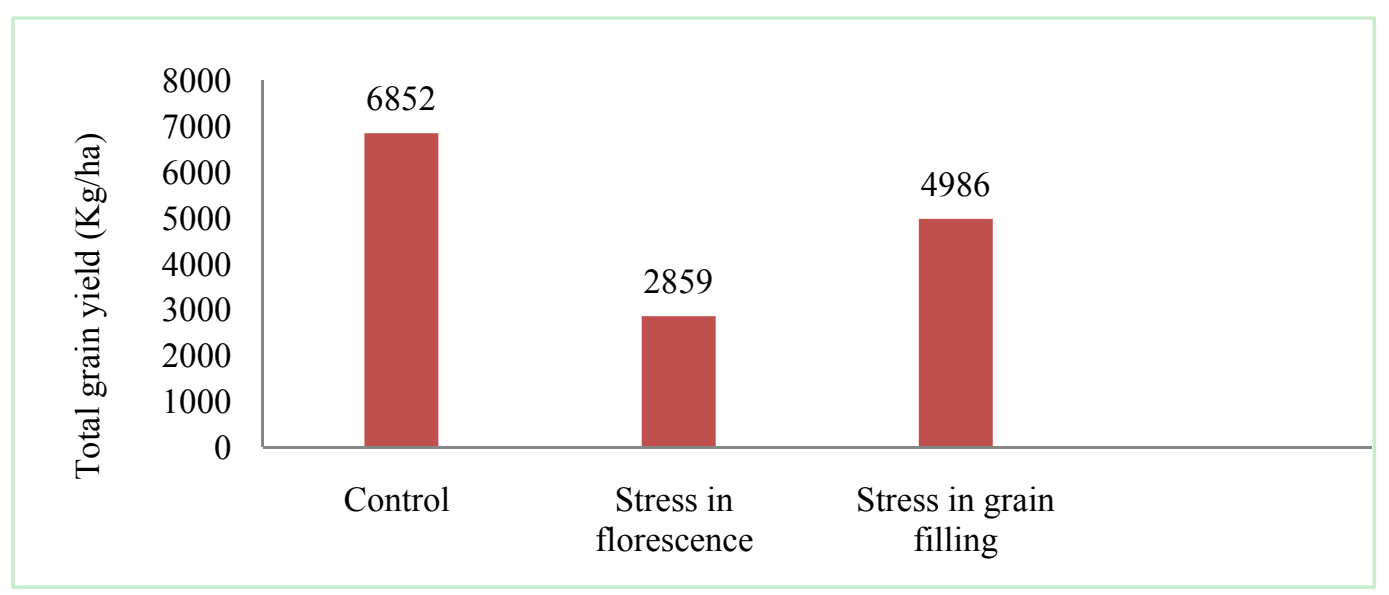

Figure 5. Effect of time of drought stress on total grain yield

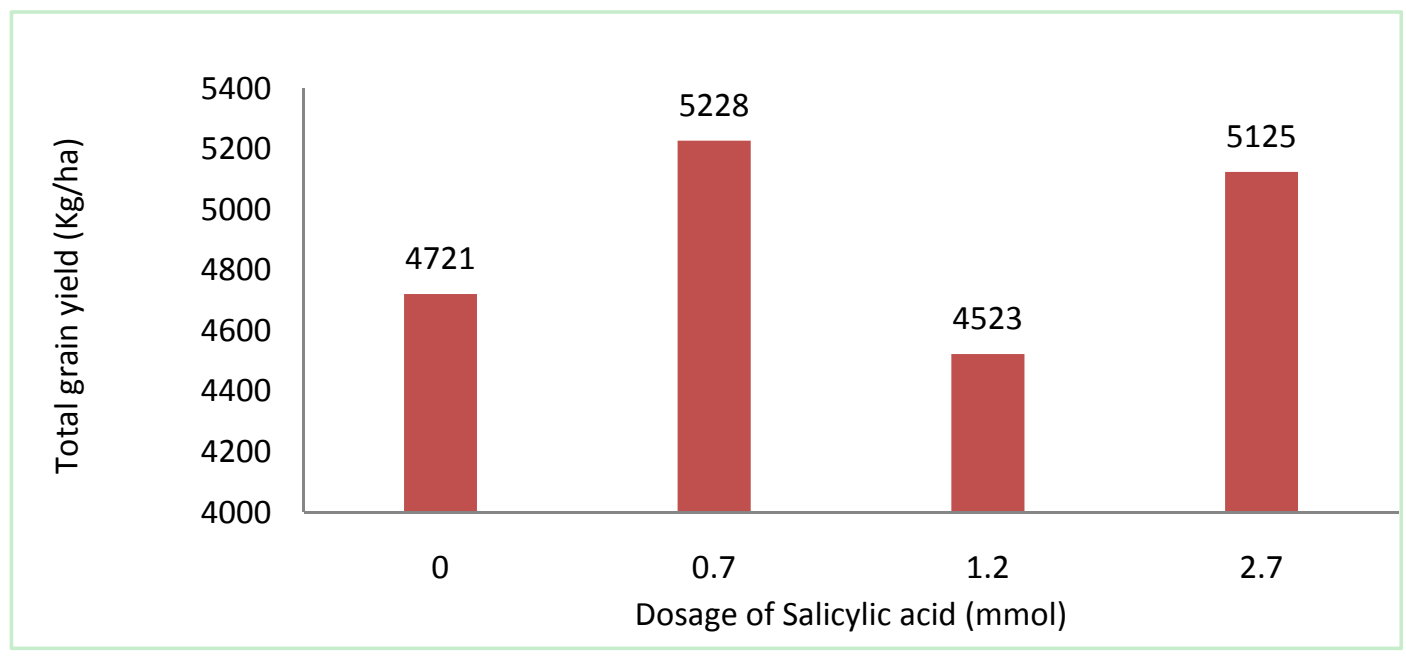

Figure 6. Effect of SA dosage on total grain yield 
Application of $0.7 \mathrm{mmol} \mathrm{SA}$ exhibited the highest grain yield while $1.2 \mathrm{mmol} \mathrm{SA}$ exhibited the lowest grain yield (Figure 6). It is suggested that salicylic acid with decreasing evapotranspiration and increasing root development let root to absorb more nutrients and under drought stress, using this treatment resulted in increased grain production compare to control. Emam et al, 2005 reported that drought stress after pollination stage in different wheat cultivars lead to decrease in grain yield.

\subsubsection{Biological Yield}

Two way interaction of SA dosage $\times$ time of application of SA showed significant effects on biological yield. Highest biological yield was produced at 0.7 ( $\mathrm{mmol}) \mathrm{SA}$ and the lowest Biological yield was produce at control (Figure 7). Stiven G and Sanaratna, 2006 reported that treated plants with SA survive more and exhibited higher relative growth rate (RGR) and more vegetative growth.

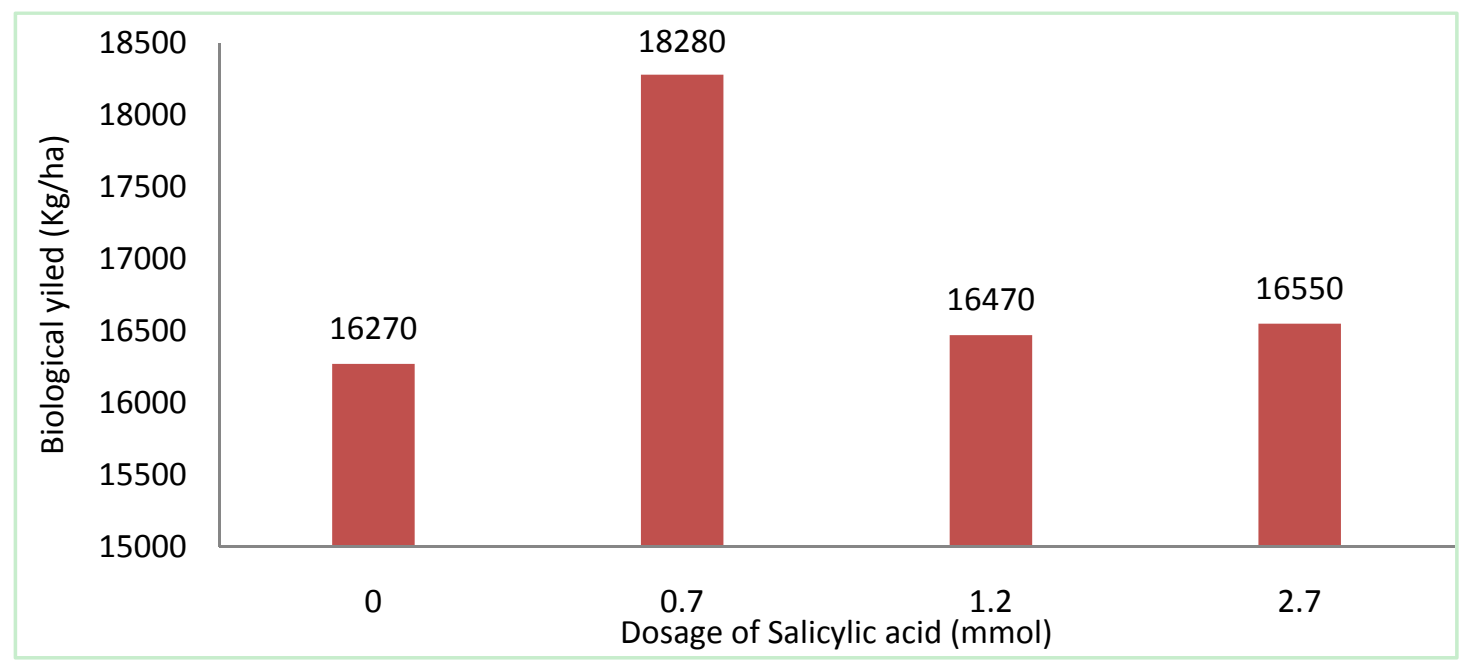

Figure 7. Effect of SA dosage on total biological yield

\subsubsection{Reverse mobilization}

Highest redistribution of photosynthetic products was in control (no stress condition) and stress in florescence exhibited the lowest (Figure 8). Considering the flowering stage, photosynthetic materials are being stored and transported to the storage organs. Drought stress at this stage may reduce $\mathrm{d}$ redistribution and the efficiency of redistribution, but role of redistribution in total yield is higher in the flowering stage and in control treatment it showed the lowest proportion (Figure 9). Role of Remobilization and redistribution of stored matter in stress condition is higher than normal condition and active metabolism is more considerable in normal condition than stress condition (Gberhand \& Doubrave, 1989).

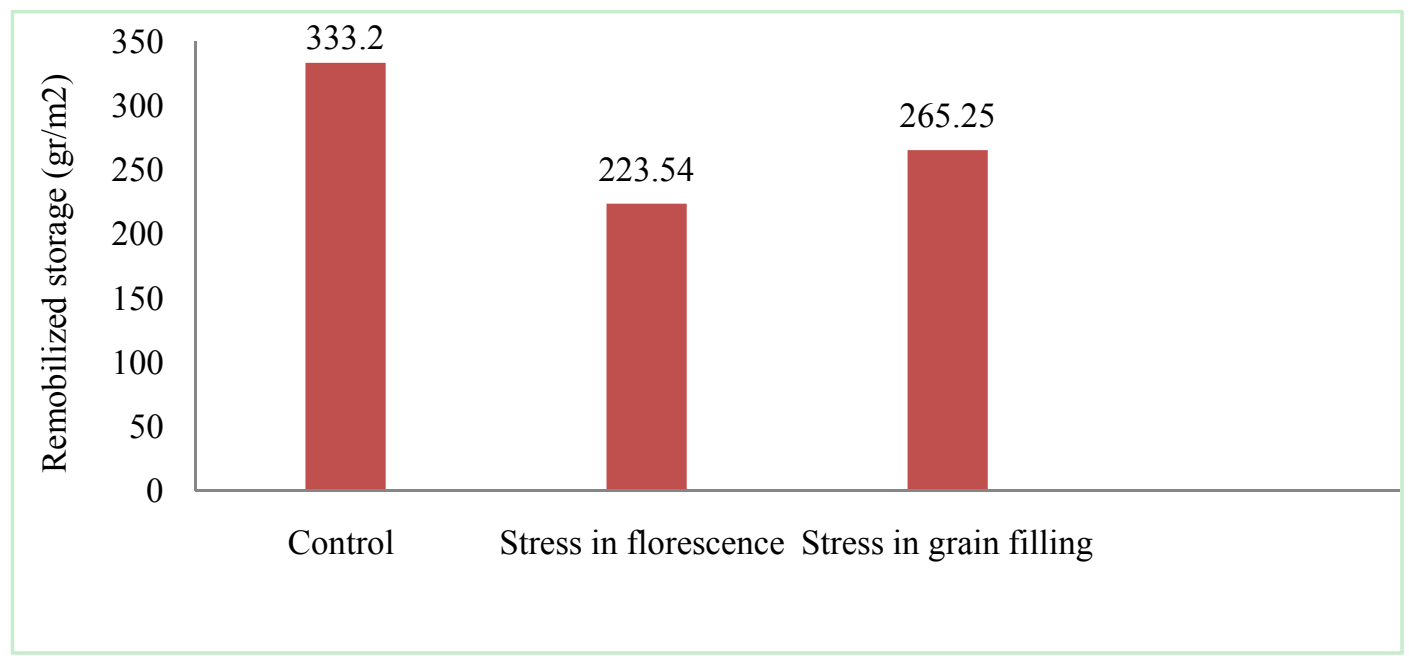

Figure 8. Effect of time of drought stress on remobilization of stored material 


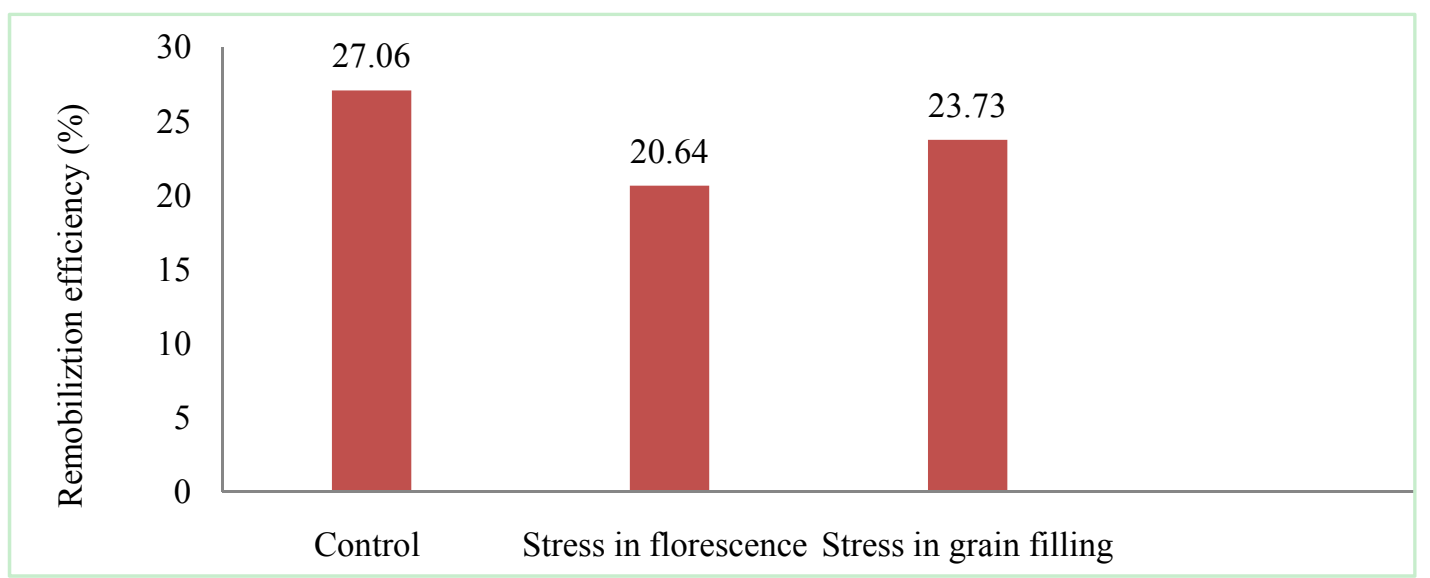

Figure 9. Effect of time of drought stress on remobilization efficiency percentage

The highest remobilization and efficiency of redistribution with treatment of time of SA application is in the vegetative growth stage (Figure 10). Higher active metabolism was observed in seed priming with SA and SA spray treatment in vegetative growth stage (Figure 11). It seems that spraying increased the vegetative growth stage, leaf index, crop growth rate, and thus increase the total biomass, which led to the increase of the metabolism and function of seed priming with SA also increased due to increase germination and vegetative growth Current yield is the percentage increase metabolism.

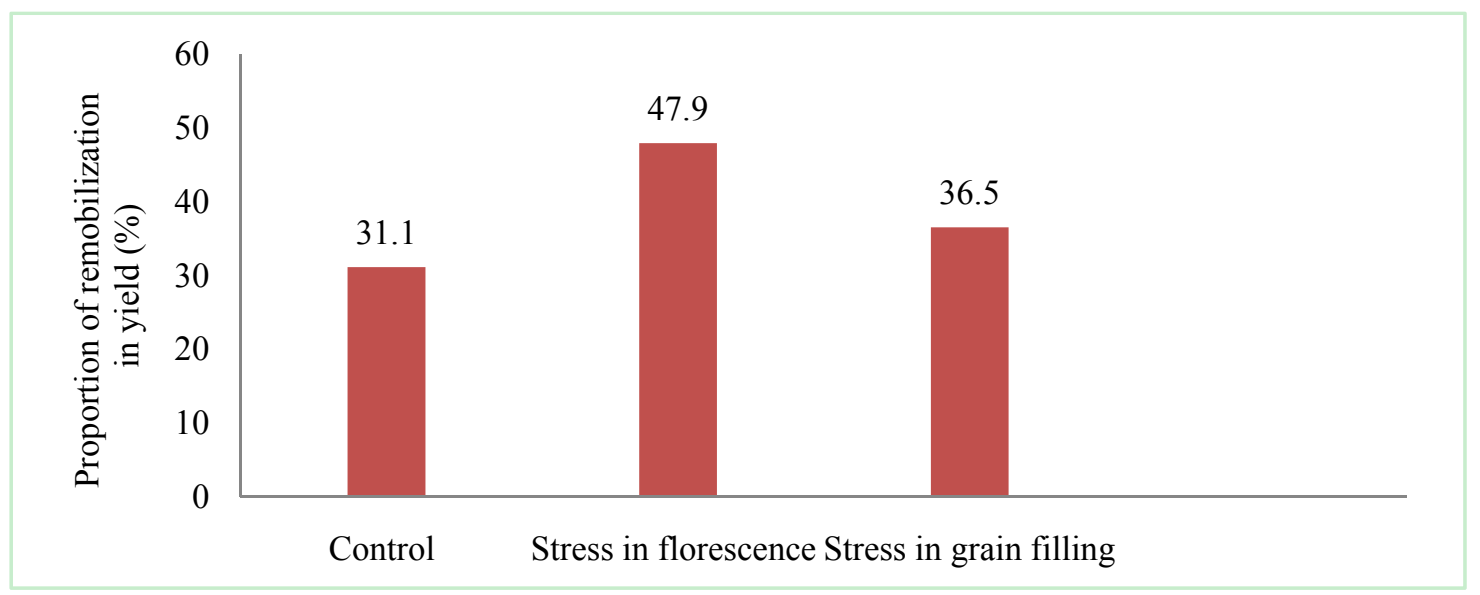

Figure 10. Effect of time of drought stress on proportion of remobilization efficiency

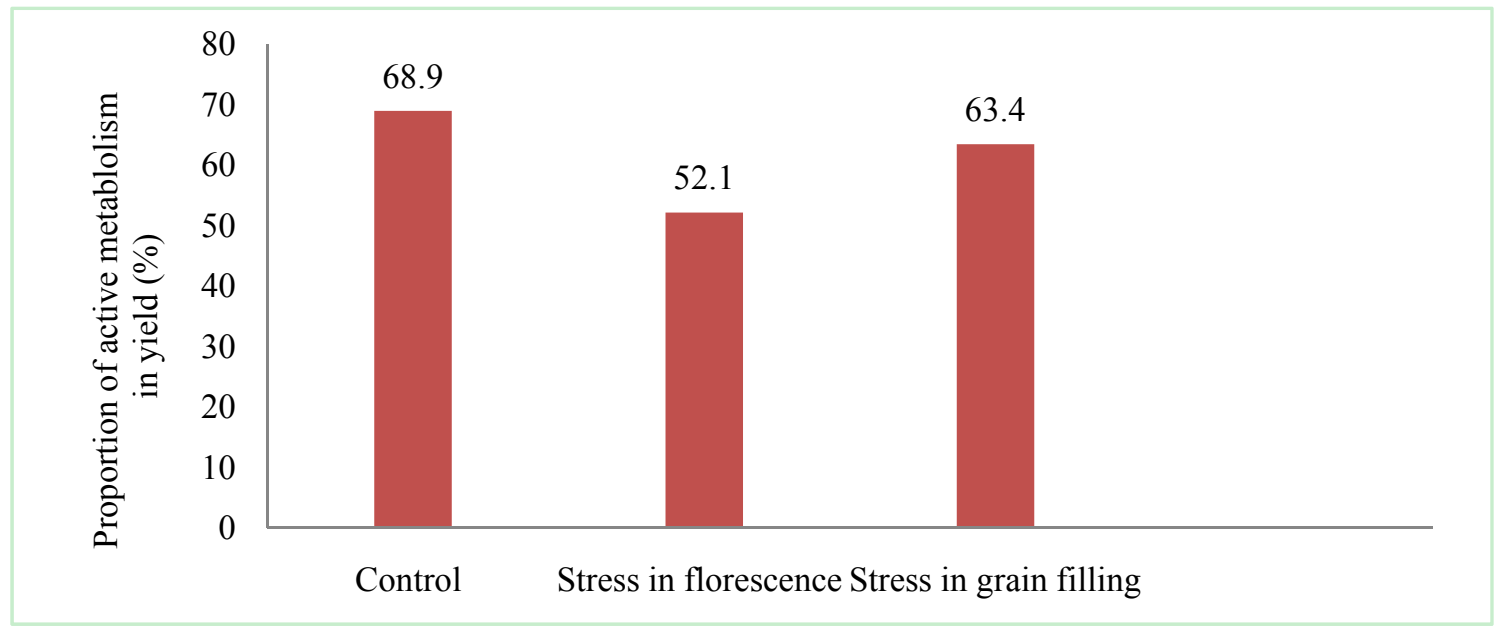

Figure 11. Effect of time of drought stress on proportion of active metabolism 


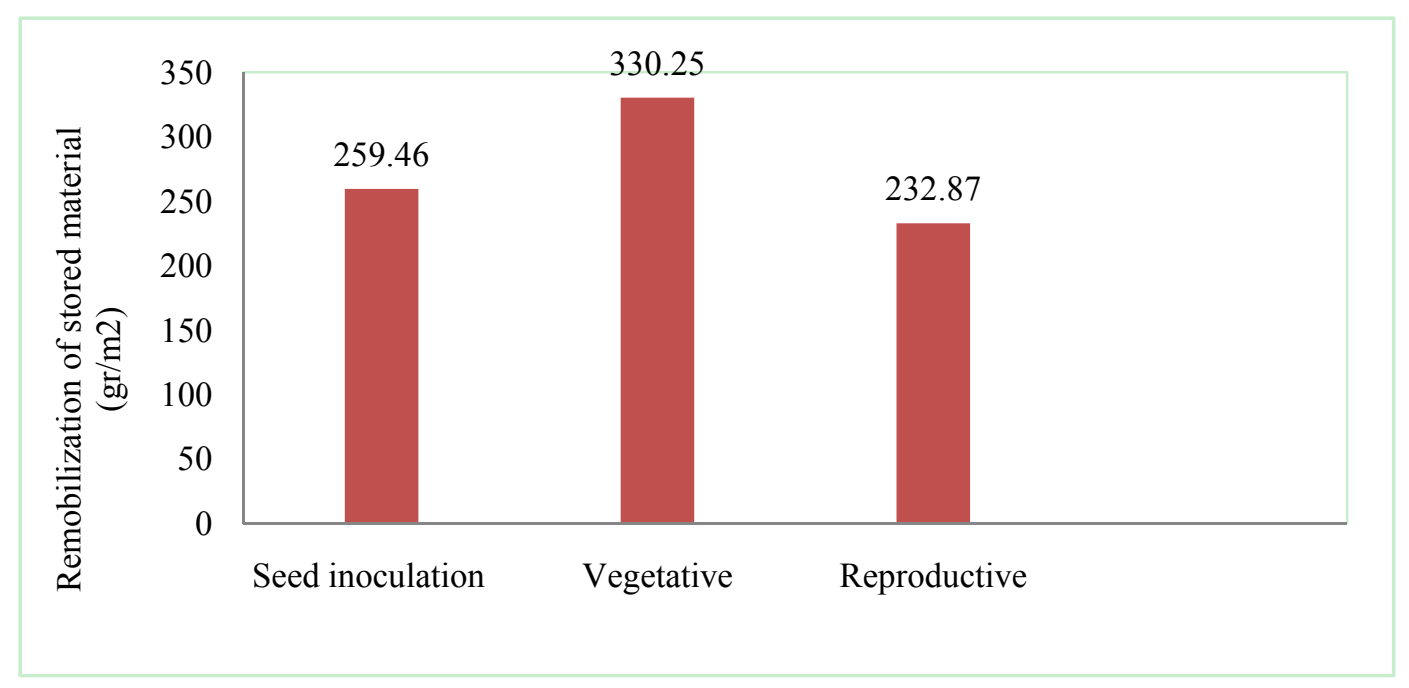

Figure 12. Effect of time of SA application on remobilization of stored material

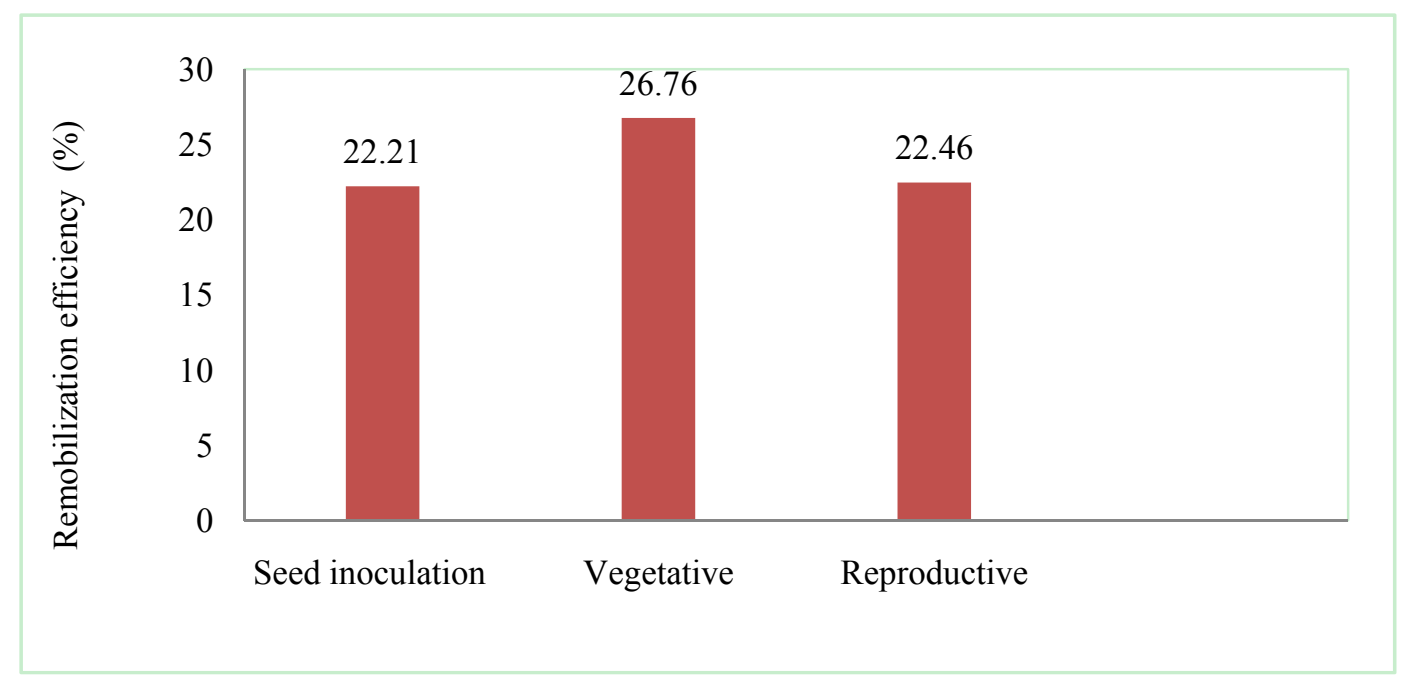

Figure 13. Effect of time of SA application on remobilization efficiency

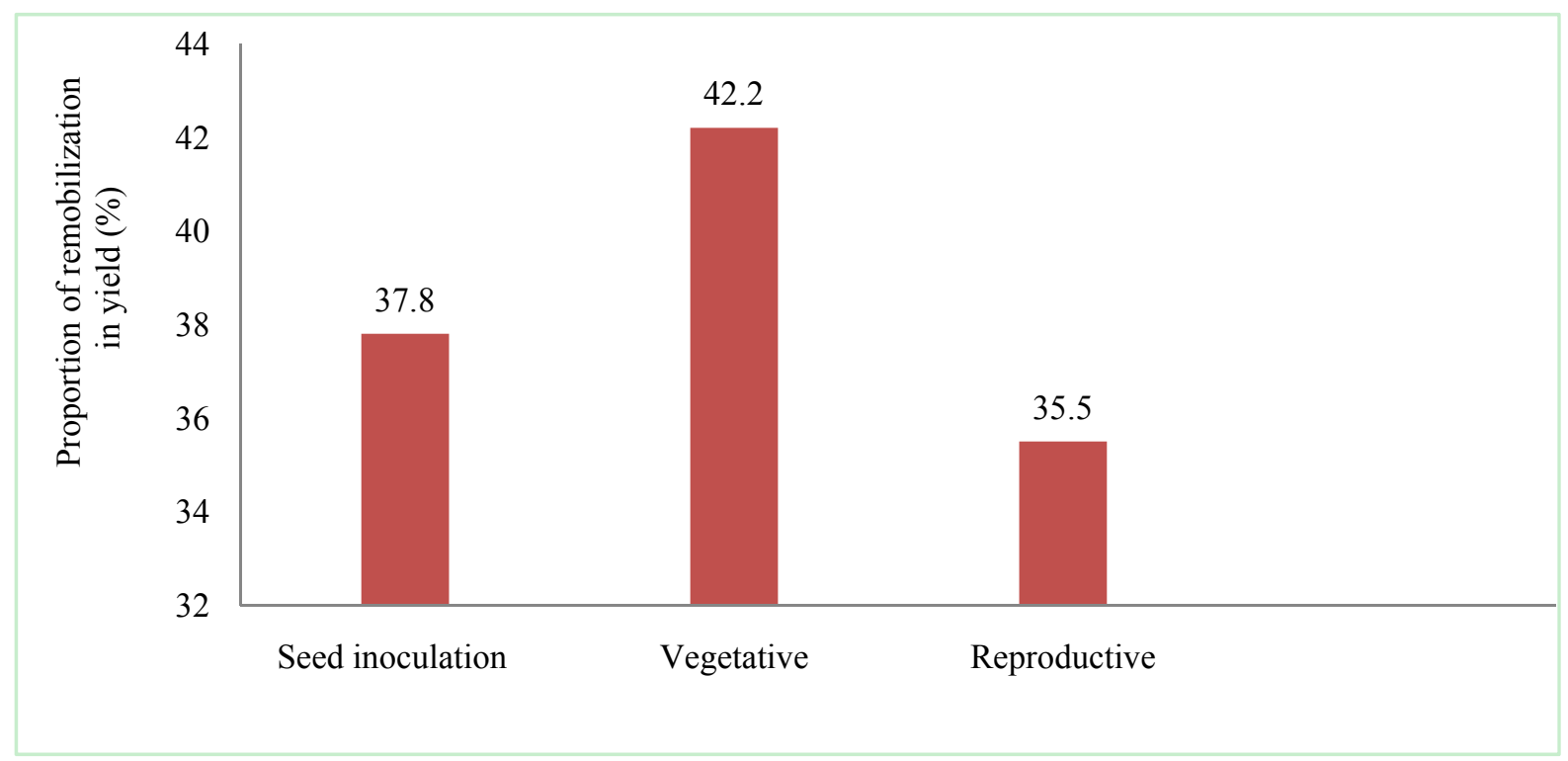

Figure 14. Effect of time of SA application on proportion of remobilization efficiency 


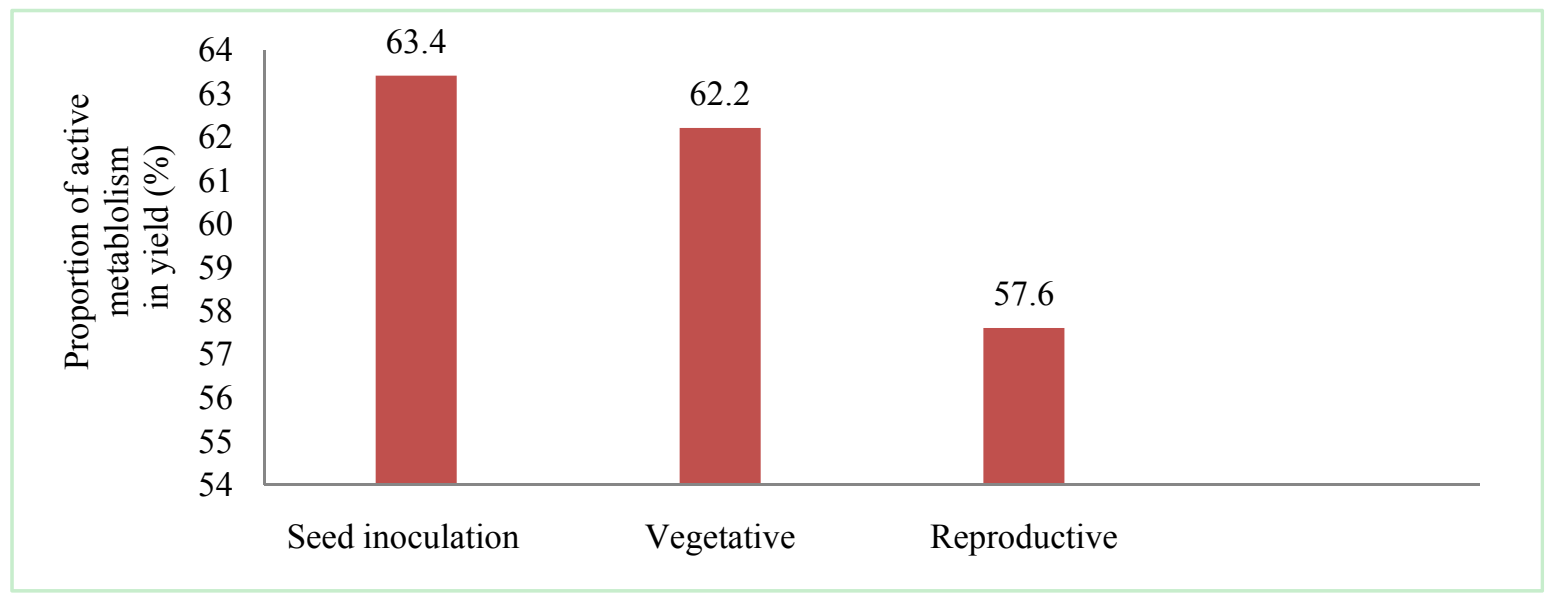

Figure 15. Effect of time of SA application on proportion of active metabolism

Low dosage of SA $(0.7 \mathrm{mmol})$ due to increase dry matter resulted in higher reverse mobilization of photosynthetic products (Figure 16). The highest reverse mobilization was observed in $(1.2 \mathrm{mmol})$ and the lowest is exhibited in control (distilled water) (Figure 16). The more dosage of SA, the higher effect of reverse mobilization of photosynthetic products was achieve and this was due to decrease in stomatal conductance and stomatal closer and limitation in Co2 traffic and as a relates lowering active photosynthesis (Figure 17, 18, 19).

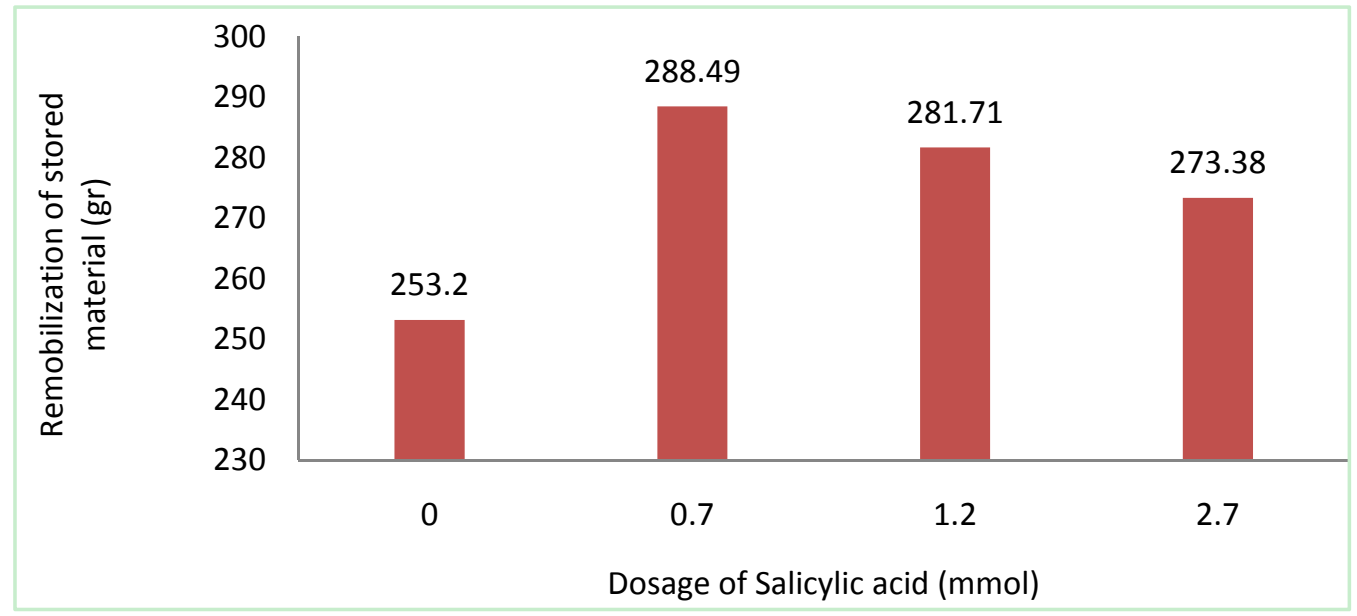

Figure 16. Effect of SA dosage on remobilization of stored material

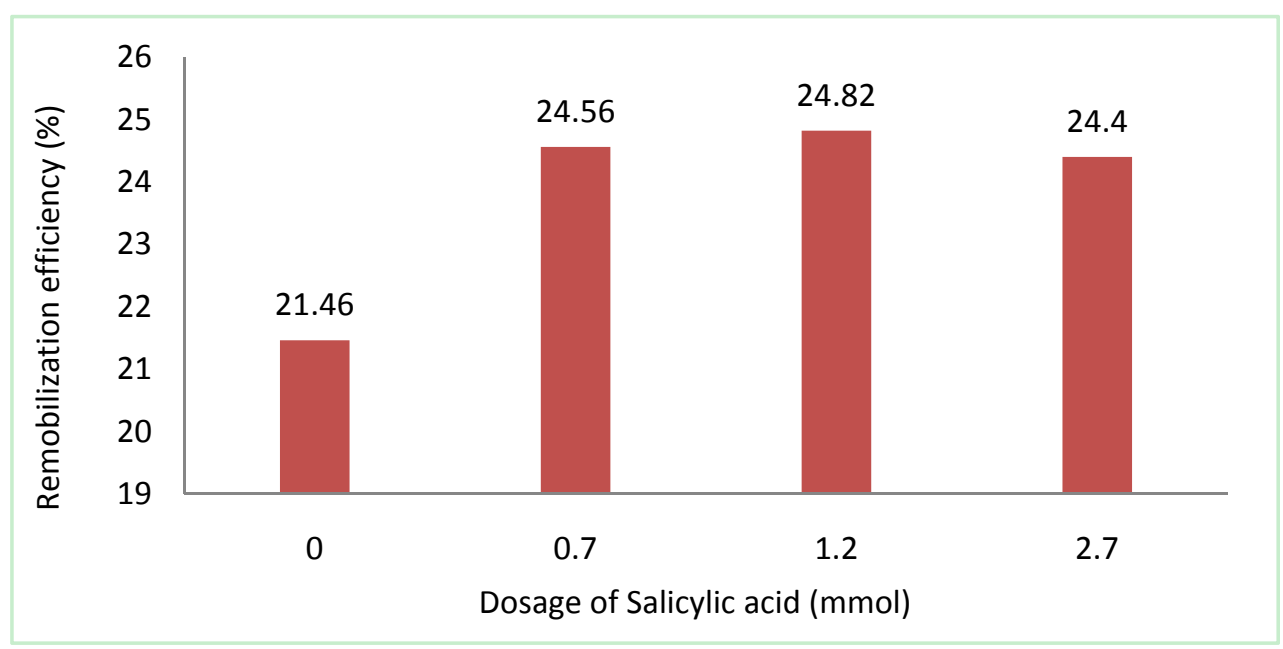

Figure 17. Effect of SA dosage on remobilization efficiency of stored material 


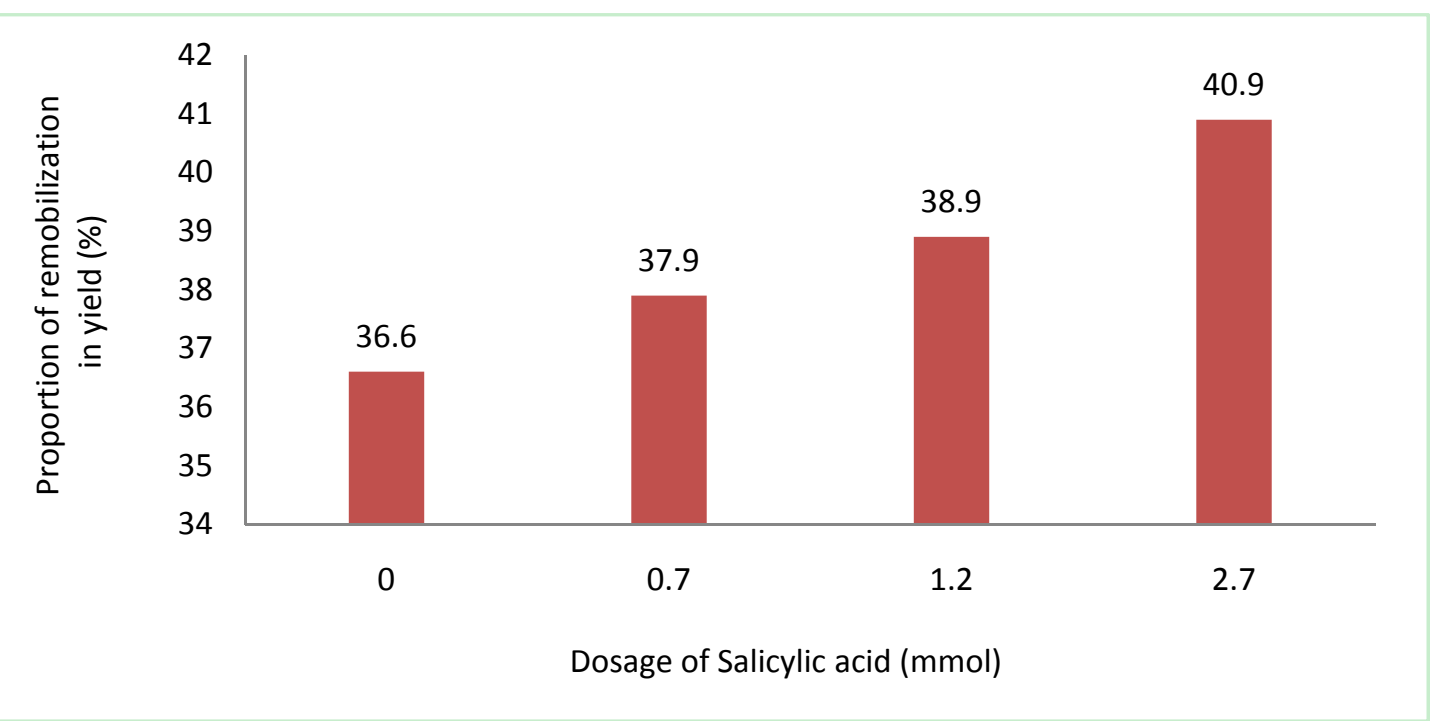

Figure 18. Effect of SA dosage on proportion of remobilization efficiency

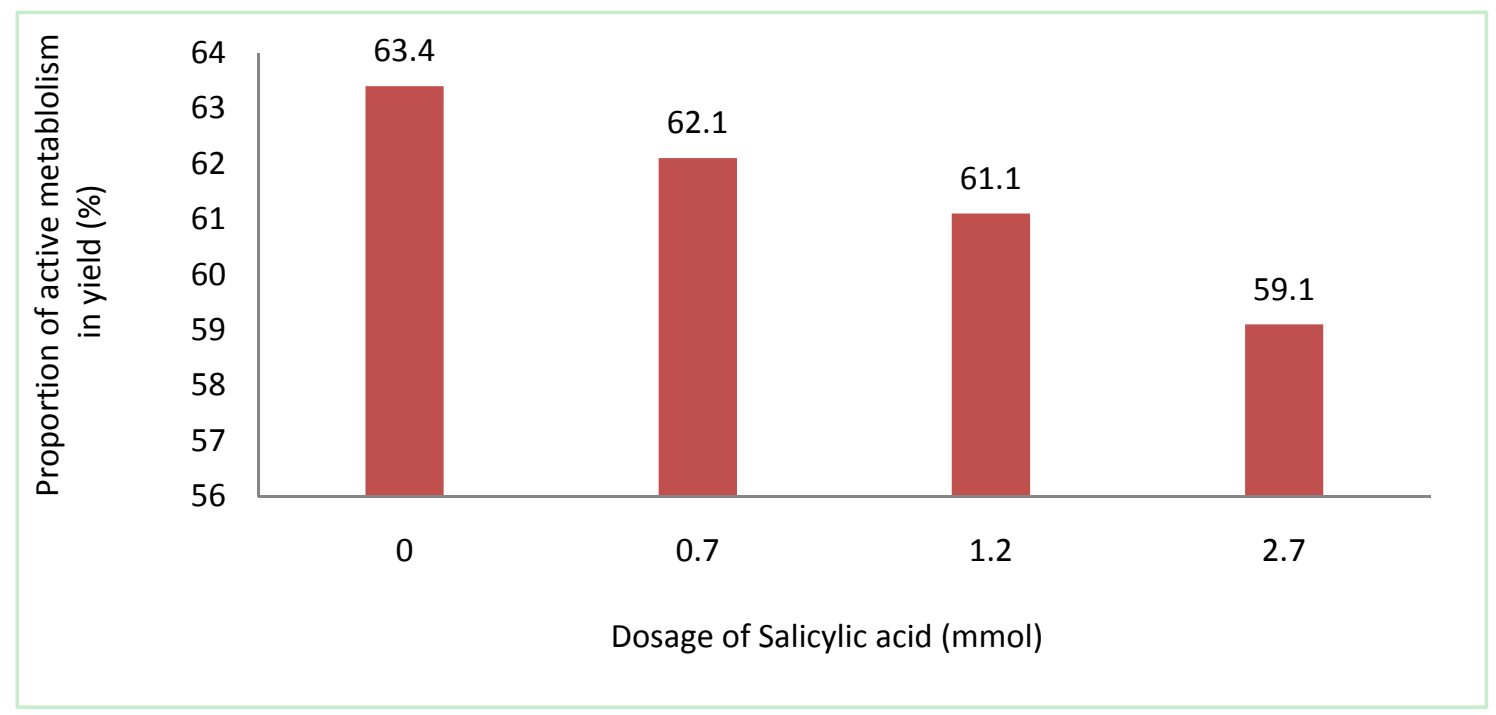

Figure 19. Effect of SA dosage on proportion of active metabolism

\section{Acknowledgment}

I am very thankful from my college in Seed certification department of Safiabad research center specially Mr. Hassan nourinejad, Saeid Khaje zadeh, Ahmad Mohammadalipour, Mis Mehri Khetshzar.

\section{References}

Bohnert, H. J., Nelcon, D. E., \& Jensen, R. G. (1995). Adaptation to environmental stresses. Plant Cell, 7 , 1099-1111.

Calderini, D. F., Reynolds, M. P., \& Slafer, G. A. (1999). Genetic gains in wheat yield and main physiological changes associated with them during the 20th century. pp. 351-377. In Satorre, E. H., and Slafer, G. A. (eds.) Wheat: Ecology and Physiology of Yield determination. New York: Food Products

Chen, Z., Iyer S, Caplan, A., Klessig, D. F., \& Fan, B. (1997). Differential accumulation of salicylic acid and salicylic acid-sensitive catalase in different rice tissues. Plant Physiol, 114, 193-201.

Day, A. D., \& Intalap, S. (1970). Some effects of soil moisture on the growth of wheat. Agron. J., 62, 27.

Eberhand, S., \& Doubrava, N. (1989). Pectic cell wall fragments regulate tobacoo thin-cell layer explants morphogenesis. Plant Cell., 1, 747-755. 
Eberhand, S., \& Doubrava, N. (1989). Pectic cell wall fragments regulate tobacco thin-cell layer exphogenesis. Plant Cell., 1, 747-745.

Emam, Y., Tafzali, A., \& Karimi., H. R. (1996). The effect of chloromequat (cycocel) on growth and development of ghods wheat. Journal of Iran Agronomy Sci., 27(1) ,23-30.

Evans, L. T. (1993). Crop Evolutin, Adaptation and Yield. Cambridge university press. pp. 500.

Gent, M. P. N. (1994). Photosynthesis reserves during grain filling in winter wheat. Agrom. J., 86 ,159-167.

Glass, A. D. M., \& Dunlop, J. (1974). Influence of phenolic acids on ion uptake. IV Depolarization of membrane potentials. Plant Physiol., 54, 855- 858.

Janda, T., Szalai, G., Tari, I., \& Paldi, E. (1999). Hydroponic treatment with salicylic acid decreases the effects of chilling injury in maize (Zea mays L.) plant. Planta, 208, 175-180.

Kang, H. M., \& Saltveit, M. E. (2002). Chilling tolerance of maize, cucumber and rice seedling leaves and roots are differentially affected by salicylic acid. Physiol Plant, 115, 571-576.

Khodary, S. E. A. (2004). Effect of salicylic acid on the growth, Photosynthesis and carbohydrate metabolism in salt- stressed maize Plants. Int. J. Agri. Biol., 6, 5-8.

Leung, J., Bouvier-Durand M., Morris, P. C., Guerrier, D., Chedfor, F., \& Giraudat, J. (1994). Arabidopsis ABA-response gene ABI 1: features of a calcium- modulated protein Phosphatase. Plant Sci., 264, $1448-1452$.

Machado, E. C., Lagoa, A. M. A., \& Ticelli, M. (1993). Source-sink relationships in wheat subjected to water stress during three productive stage. Revista Brasileira de Fisiologia Vegetal., 5(2), 145-150.

Papakusta, D. K., \& Gagianas, A. A. (1991). Nitrogen and dry matter accumulation, remobilization and losses for Mediterranean wheat during grain filling. Agronomy Journal, 83, 864-870.

Quarrie, S. A., \& Jones., H. G. (1979). Genotypic variation in leaf water potential stomatal conductance and abssisic acid concentration in spring wheat subjected to artificial drought stress ann. B.ot., 44, 323-332.

Robertson, M. J., \& Guinta, F. (1994). Responses of spring wteat exposed to pre-anthesis water stress. Australian Journal of Agricultural Research, 45, 19-35.

Saini, H. S., \& aspinall, d. (1981). Effect ofwater deficitonsporogenesis in when. Ann bot., 48, 623-635.

Sakhabutdinova, A. R., Fatkhutdinova, D. R., Bezrukova, M. V., \& Shakirova, F. M. (2003). Salicylic acid prevents the damaging action of stress factors on wheat plants. Bulg J. Plant Physiol., 29, 314-319. Special Issue.

Singh, B. R., \& singh, D. P. (1992). Effects of irrigation on plant water relations in the conopy profiles ofsorghum.Maize and pearl millet. Crop Res., 5(3), 412-416.

Singh, J., \& Patel, A. (1996). Dry matter distribution different parts of wheat b under water stress at various growth stage. Field crop abstracts, 49(11), 10-16.

Yusuf, M., Hasan, S. A., Ali, B., Hayat, S., Fariduddin, Q., \& Ahmad, A. (2008). Effect of salicylic acid on salinity induced changes in Brassica juncea. J. Integrative Plant Biol., 50, 1196-1102. 